\title{
Calcitonin induces connective tissue growth factor through ERK1/2 signaling in renal tubular cells
}

\author{
Misa Nakamura, ${ }^{1,2,3}$, Takashi Ozaki ${ }^{1}$, Aiko Ishii, \\ Masayoshi Konishi' ${ }^{2}$, Yuji Tsubota ${ }^{2}$, Toru Furui ${ }^{2}$, \\ Hayato Tsuda ${ }^{2}$, Ichiro Mori ${ }^{1}$, Kiichiro Ota ${ }^{2}$ and \\ Kennichi Kakudo ${ }^{1}$

\section{${ }^{1}$ Department of Pathology} \\ Wakayama Medical University \\ Wakayama 641-0012, Japan \\ ${ }^{2}$ Department of Rehabilitation \\ Osaka Kawasaki Rehabilitation University \\ Osaka 597-0104, Japan \\ ${ }^{3}$ Corresponding author: Tel, 81-72-421-3347; \\ Fax, 81-72-421-3347; E-mail, nakamuram @ kawasakigakuen.ac.jp \\ DOI 10.3858/emm.2009.41.5.034
}

Accepted 10 December 2008

Abbreviations: CT, calcitonin; CTGF, connective tissue growth factor

\begin{abstract}
Calcitonin (CT), a polypeptide hormone, plays important roles in a variety of physiological processes. CT has been used clinically to treat osteoporosis and humoral hypercalcemia of malignancy. In order to clarify the pharmacological effects of CT in the kidney, we identified potential downstream genes induced by CT in the renal cells. Using a cDNA subtraction hybridization method, we identified connective tissue growth factor (CTGF) as a CT-induced gene in the porcine renal cell line, LLC-PK1. Furthermore, we found that CT-mediated induction of the gene was not inhibited by cycloheximide, which suggests that CTGF gene was not induced by an increased synthesis of regulating proteins. Therefore, CTGF is an immediate early gene. We further demonstrated that the regulation of CTGF gene expression by CT involved the ERK1/2 pathway, because PD98059, a MEK1 inhibitor, partially inhibited the mRNA expression of CTGF induced by CT. CT-induced CTGF protein expression was also observed in vivo. Our present findings suggest that $C T$ induces the transcription of CTGF through ERK1/2 phosphorylation. We also identified twelve other genes induced by CT that, like CTGF, were related to wound healing. These results suggest that CT may have an effect on renal differentiation and wound healing in the kidney.
\end{abstract}

Keywords: calcitonin; connective tissue growth factor; extracellular signal-regulated MAP kinases; gene expression regulation; kidney; wound healing

\section{Introduction}

Calcitonin (CT) is a polypeptide hormone secreted by the parafollicular cells of the thyroid gland (Foster, 1964). CT acts physiologically to reduce serum calcium levels by inhibiting osteoclastic bone resorption and promoting urinary calcium excretion (Bijvoet et al., 1971). In the kidney, sodium $\left(\mathrm{Na}^{+}\right)$ reabsorption in the proximal renal tubule is dependent mainly on the activity of the $\mathrm{Na}^{+}, \mathrm{K}^{+}$-ATPase and the apical $\mathrm{Na}^{+} / \mathrm{H}^{+}$exchanger. Chakraborty et al. (1994) reported that CT affects the activity of proximal tubular $\mathrm{Na}^{+}$transport systems, with the effect depending on the cell cycle phase in LLC-PK1 cells. The inhibition of phosphate uptake by CT in the proximal renal tubule has also been reported (Muff et al., 1994). CT has been used clinically to treat osteoporosis and humoral hypercalcemia of malignancy (McDermott et al., 1987; Zaidi et al., 1990). However, the pharmacological effects of CT in the kidney are unknown.

LLC-PK1 cells, which are isolated from the cortex of the porcine kidney, are widely used as a model of proximal tubules (Force et al., 1992). Many studies concerning the CT signaling pathway and its function have been performed since the CT receptor was first cloned from these cells (Lin et al., 1991). Yoshida et al. (1999) reported that CT upregulated 25-hydroxyvitamin D3 1 $\alpha$-hydroxylase via the PKC pathway in LLC-PK1 cells. In our previous study, we found that the transcription of the NF-IL3A and urokinase type-plasminogen activator (UPA) was induced by CT through MAPK pathway in LLC-PK1 cells (Nakamura et al., 2002). These results suggest that CT has functions other than regulating calcium excretion.

In this study, we identified CT-induced genes in LLC-PK1 cells and clarify whether the induction involves MAPK pathway of connective tissue growth factor (CTGF) by CT.

\section{Results}

Isolation of genes induced by CT

In order to identify specific genes that are induced 
by CT in renal cells, we created a subtraction library of clones from LLC-PK1 cells treated with CT for 3 h. A total of 13 known genes were up-regulated by CT, including CTGF, urokinase-type plasminogen activator (UPA), NF-кB, IL-8, interleukin-3 promoter transcriptional activator (NF-IL3A), thrombospondin, heat shock protein 70, FGF receptor, apolipoprotein B, lactoferrin, Gs, mitochondrial ATP synthase b-subunit and heparin-binding growth factor receptor k-sam (Table 1 ). The effects of CT on the expression levels of these genes were examined by Northern blot analysis (Figure 1).

\section{CTGF is a CT-induced gene}

CT increased CTGF mRNA (2.4 kb) levels to a maximum (5.8 fold) after $1 \mathrm{~h}$ of $\mathrm{CT}$ treatment (Figure 2A). In order to test the possibility that CT regulates CTGF expression through de novo protein synthesis of cytokines or transcription factors, the cells were preincubated with a protein synthesis inhibitor, cycloheximide $(10 \mu \mathrm{g} / \mathrm{ml})$, for $3 \mathrm{~h}$, then further incubated with CT $\left(10^{-8} \mathrm{M}\right)$ for $3 \mathrm{~h}$. We observed that CT-mediated induction of CTGF was not inhibited by cycloheximide (Figure 2B). These results suggest that the induction of CTGF gene expression by $\mathrm{CT}$ is not mediated by de novo protein synthesis.

\section{CT induces CTGF through the ERK pathway}

We have found that CT-induced ERK1/2 phosphorylation is mediated by the MEK-ERK pathway
(Nakamura et al., 2002) (Figure 3A). In order to determine if CTGF induction involves this signaling pathway, the effect of ERK inhibition was determined. Cells were preincubated with $50 \mu \mathrm{M}$ PD98059 for $30 \mathrm{~min}$. The cells were further incubated with $10^{-8} \mathrm{M} \mathrm{CT}$ for $1 \mathrm{~h}$. Pretreatment of the cells with PD98059 caused a significant decrease in CTGF mRNA expression $(P<0.05)$

Table 1. List of genes induced by CT in LLC-PK ${ }_{1}$.

\begin{tabular}{lcc}
\hline \multicolumn{1}{c}{ Gene } & Accession No. & Fold $^{*}$ \\
\hline $\begin{array}{l}\text { Urokinase-type plasminogen } \\
\text { activator }\end{array}$ & X02724 & 17.50 \\
NF-kB & M58603 & 7.49 \\
IL-8 & $\mathrm{M} 86923$ & 3.00 \\
IL-3 promoter transcriptional & $\mathrm{S} 79880$ & 2.74 \\
$\quad$ activator (NF-IL3A) & & \\
Connective tissue & $\mathrm{A}$ 0059051 & 2.46 \\
growth factor & & \\
Thrombospondin & $\mathrm{X} 14787$ & 2.01 \\
Heat shock protein 70 & $\mathrm{~L} 12723$ & 1.92 \\
FGF receptor & $\mathrm{X} 56191$ & 1.67 \\
Apolipo-protein B & $\mathrm{L} 11235$ & 1.65 \\
Lactoferrin & $\mathrm{L} 24753$ & 1.63 \\
Gs & $\mathrm{C} 95011$ & 1.59 \\
Mitochondrial ATP & $\mathrm{X} 06088$ & 1.52 \\
synthase b-subunit & & \\
Heparin-binding growth & $\mathrm{M} 35718$ & 1.44 \\
factor receptor k-sam & & \\
\hline
\end{tabular}

*The fold was determined from a comparison of RNA from cells treated with and without $\mathrm{CT}$ for $3 \mathrm{~h}$.
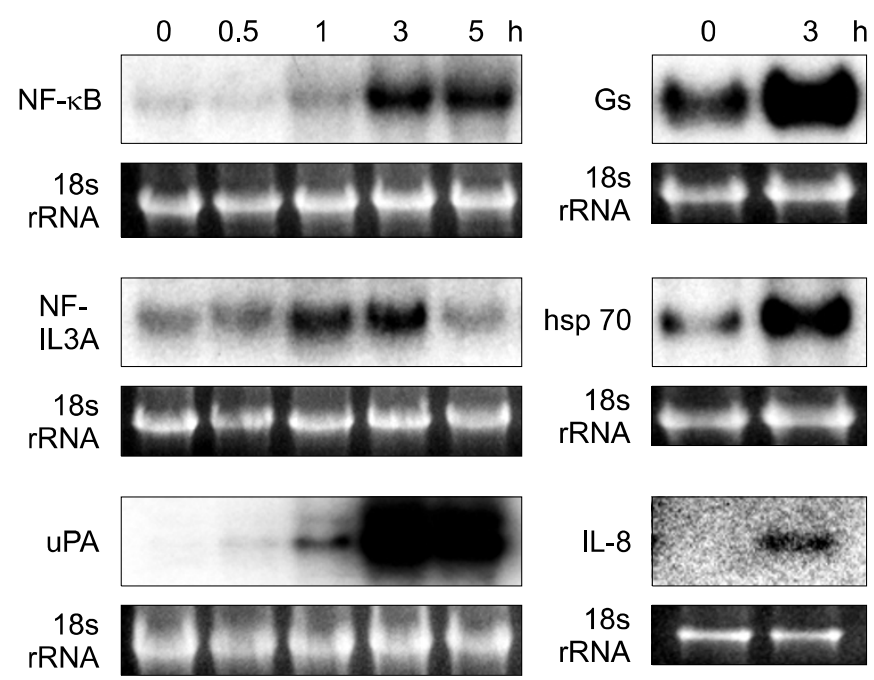
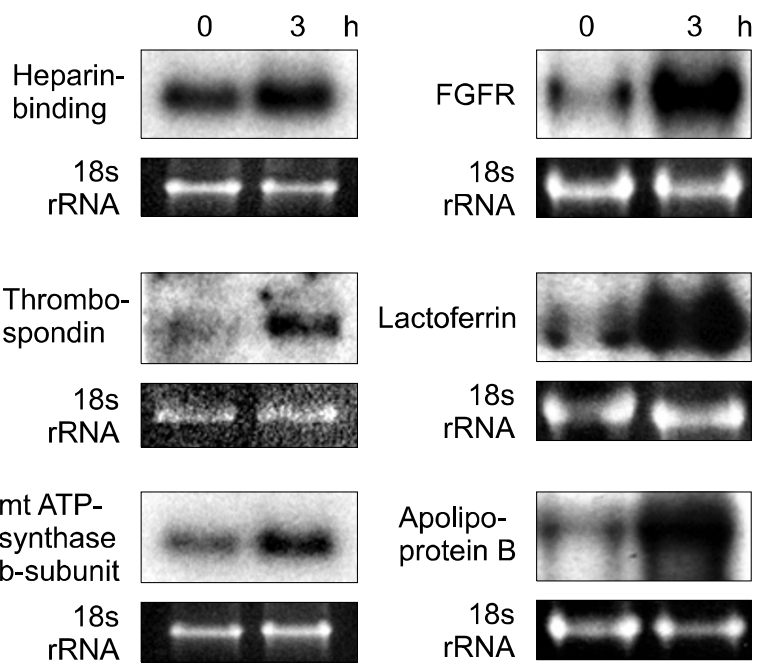

Figure 1. Effect of CT on mRNA expression levels of 12 genes in LLC-PK1 cells. Cells were incubated with $10^{-8} \mathrm{M}$ CT for the indicated times. The mRNA levels were evaluated by Northern blot hybridization. In order to control for equal loading of the gels, the expression of each gene was normalized to the levels of 18s rRNA. 
A

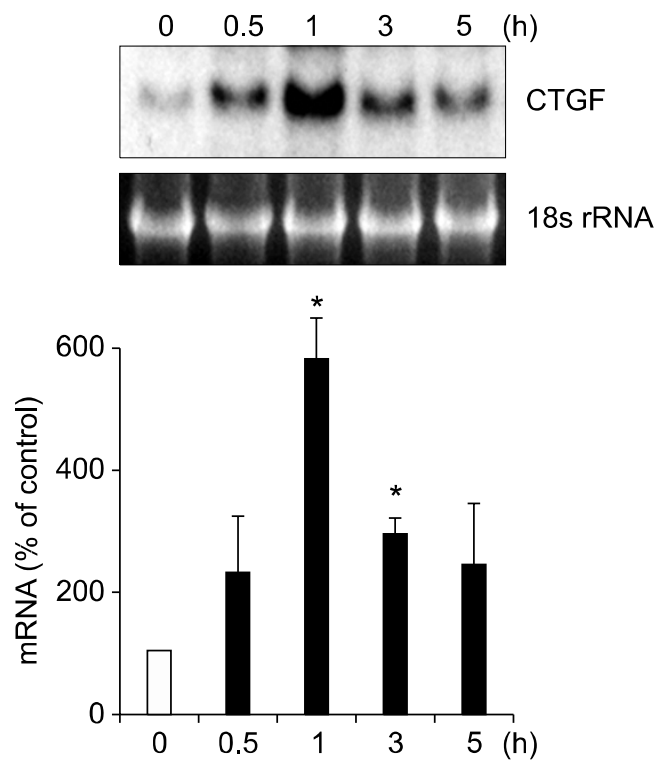

B
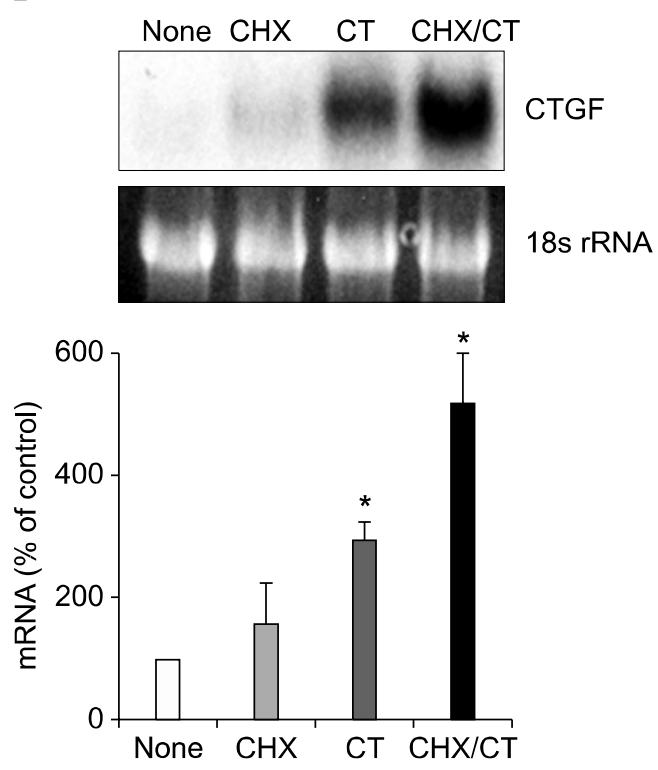

Figure 2. Effects of various reagents on CT-induced expression of CTGF in LLC-PK1. (A) Induction of CTGF mRNA in LLC-PK1 cells. Cells were incubated with $10^{-8} \mathrm{M} \mathrm{CT}$ for the indicated times. CTGF mRNA expression levels were evaluated by Northern blot hybridization. The ratios of CTGF to $18 \mathrm{~s}$ rRNA were calculated. An arbitrary value of 100 was assigned to the control $(0 \mathrm{~h})$. Data are presented as means \pm SEM of three experiments. ${ }^{*} P<$ 0.05, compared with control. (B) Influence of cycloheximide on CT-induced expression of CTGF in LLC-PK1. LLC-PK1 cells were treated with cycloheximide (CHX; $10 \mu \mathrm{g} / \mathrm{ml})$ and/or $10^{-8} \mathrm{M} \mathrm{CT}$ for the indicated times. CTGF mRNA expression levels were evaluated by Northern blot hybridizarion. NONE, without any treatment; $\mathrm{CT}$, CT treatment for $3 \mathrm{~h}$; $\mathrm{CHX}, \mathrm{CHX}$ treatment for $3 \mathrm{~h}$; $\mathrm{CHX/CT}, \mathrm{CHX}$ treatment for $3 \mathrm{~h}$ then followed by $\mathrm{CT}$ treatment for $3 \mathrm{~h}$. The ratios of CTGF to $18 \mathrm{~s}$ rRNA were calculated. An arbitrary value of 100 was assigned to the control (NONE). Data are presented as means \pm SEM of three experiments. ${ }^{*} P<0.05$, compared with control.

(Figure 3B).

\section{CT induces CTGF expression in vivo}

In order to assess whether CT induces CTGF in vivo, CT was injected into the tail veins of mice. Three hours after injection, CTGF expression in the kidneys was analyzed by immunohistochemistry. The specificity of the CTGR antibody was confirmed using human cirrhosis as positive control. CTGF immunostaining was observed in the renal tubular epithelium in the inner zone of renal cortex of CT injected mice. Little or no staining was identified in the vehicle-injected mice (Figure 4).

\section{Discussion}

Using cDNA subtraction hybridization, we have identified CTGF as a CT-responsive gene. mRNA expression of the gene was increased within $1 \mathrm{~h}$ after CT treatment, and did not require any new protein synthesis. CTGF belongs to the family of low-affinity insulin-like growth factor-binding proteins, which consists of Mac25, the nov oncogenes and cyr61 (Kim et al., 1979). It is also classified as a member of the CCN (CYR61, CTGF and NOV) family (Bork et al., 1993; Lau et al., 1999). CTGF is an immediate early response gene (Igarashi et al., 1993), which are generally induced by a variety of mediators.

All progressive renal diseases are the consequence of a process of destructive fibrosis. CTGF has a fibrosis-promoting effect, as does angiotensin II, endothelin-1 and TGF- $\beta$ (Eddy, 2000). CTGF mRNA levels have been reported to be elevated in various types of renal disease characterized by glomerulosclerosis, tubulointerstitial fibrosis, and diabetic renal disease (Ito et al., 1998; Thomson et al., 2008). In addition, CTGF was found to be upregulated in wound healing and renal fibrosis (Blom et al., 2001).

The exact extent and time-course of activation of the ERK, JNK/SAPK and p38 MAPK cascades by particular stimuli are highly distinctive and characteristic for each stimulus (Cano et al., 1995; Hazzalin et al., 1998). Previously, we demonstrated that CT activation of LLC-PK1 cells stimulated ERK1/2 phosphorylation through MEK (Nakamura et al., 2002), however, CT suppressed ERK1/2 constitutive activation in human cancer cells (Nakamura et al., 2007). We showed that ERK activation by CT is abolished completely by 
A

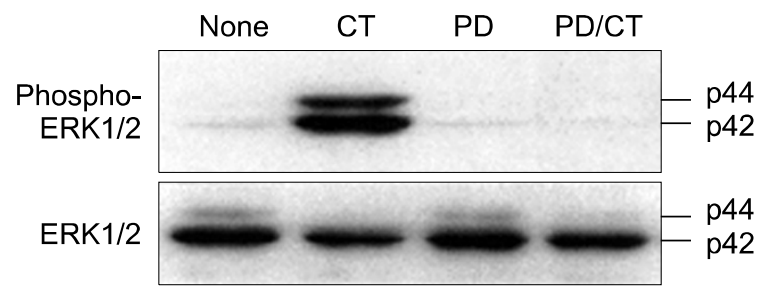

B
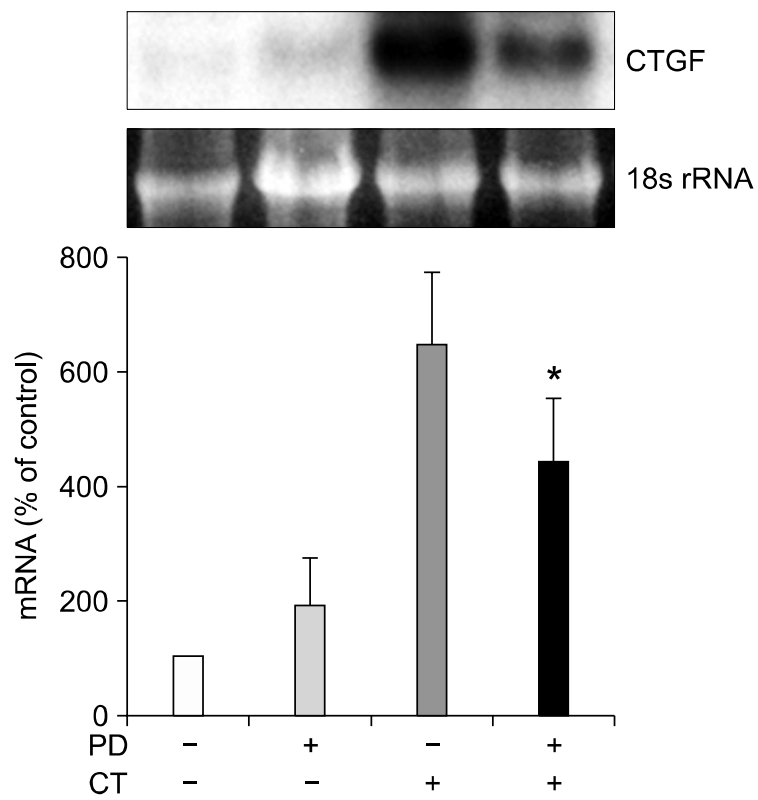

Figure 3. Effects of ERK1/2 pathway on CTGF expression by CT in LLC-PK1. (A) Effects of CT and PD on CTGF expression. Subconfluent LLC-PK1 cells were treated with $10^{-8} \mathrm{M}$ CT or $50 \mu \mathrm{M}$ PD98059 for the indicated times. CT, $10^{-8} \mathrm{M}$ CT treatment for $30 \mathrm{~min}$; PD, $50 \mu \mathrm{M}$ PD98059 treatment for $30 \mathrm{~min}$; CT/PD, treatment of $50 \mu \mathrm{M}$ PD98059 for $30 \mathrm{~min}$ followed by $10^{-8} \mathrm{M}$ CT treatment for 30 min (B) Influence of PD98059 on CT-induced expression of CTGF. Cells were preincubated with $50 \mu \mathrm{M}$ PD98059 for 30 min followed by $10^{-8} \mathrm{M}$ CT incubation for $30 \mathrm{~min}$. CTGF mRNA expression levels were evaluated by Northern blot hybridization. The ratios of CTGF to 18s rRNA were calculated. An arbitrary value of 100 was assigned to the control. Data are presented as means \pm SEM of three experiments. ${ }^{*} P<0.05$, compared with $10^{-8} \mathrm{M}$ CT-treated cells.

PD98059, however, CTGF expression induced by CT was a partially inhibited by PD98059. These findings suggest that the induction of CTGF transcription by CT is accomplished, in part, via the ERK pathway.

The regulation of CTGF mRNA and protein expression by the ERK signaling pathway has also been demonstrated in the lung stimulated by TGF- $\beta$ (Xie et al., 2005). CTGF induces extracellular matrix protein production, cell migration, and actin cytoskeletal rearrangements through ERK and protein kinase $B$ in human mesangial cells (Crean et al., 2002). Hahn et al. (2000) observed that CTGF mRNA in mesanglial cells was increased by serotonin (5-HT) and lysophosphatidic acid (LPA), and that these increases were dependent on Rho proteins, but not ERK1/2 phosphorylation. In retinal vascular cells, VEGF-induced CTGF expression was dependent upon the PI3-kinase-AKT pathway, but independent of ERK phosphorylation (Suzuma et al., 2000). Heusinger-Ribeiro et al. (2001) have demonstrated the roles of small GTPase RhoA and an intact cytoskeleton in mediating stimulation of CTGF expression by LPA or TGF- $\beta$ in a renal fibroblast cell line. These results suggest that CTGF expression is regulated by different stimuli acting via different pathways in different cell types.

In the present study, CT-induced CTGF expression was confirmed in tubular epithelium of mice. These results support the idea that CT-induced CTGF expression is mediated through CT binding sites in renal tubule cells. We have shown expression of CTR mRNA in rat kidney by ISH and demonstrated intensive CTR expression in the proximal and distal tubule (Ishii et al., 2004).

In transgenic mouse embryos and fetuses, the promoter activity of the CTR gene has been shown to be developmentally regulated in a number of tissues (Jagger et al., 1999, 2000), showing an important role for CTRs in mammalian morphogenesis. It has also been reported that various tissues and organ systems including kidney produce CTGF in a specific temporal-spatial pattern during embryogenesis, which supports a role for CTGF in cellular differentiation and development during prenatal life (Surveyor et al., 1999). Therefore, CTGF-induction by CT in the kidney may play a role in renal differentiation in early stages of development.

In addition to CTGF, we identified 12 other CT-regulated genes using cDNA subtraction hybridization. Most, like CTGF, are involved in inflammation and wound healing. In cultured cell models, CTGF, UPA and HSP70 genes are induced by wounding (Pawar et al., 1995). Song et al. (2007) reported that UPA forms a complex with protein $\mathrm{C}$ inhibitor, which is known to regulate blood coagulation, wound healing, and tumor metastasis, and the two proteins are colocalized in the renal proximal tubular epithelial cells. NF- $\mathrm{kB}$ has been reported to be upregulated in uroteropelvic junction obstruction (Ruiz-Deya et al., 2002). Thrombospondin is known to play a role in embryogenesis, wound healing, angiogenesis, and tumorigenesis (Taraboletti et al., 1992).

In summary, we showed that CT in pharmaco- 

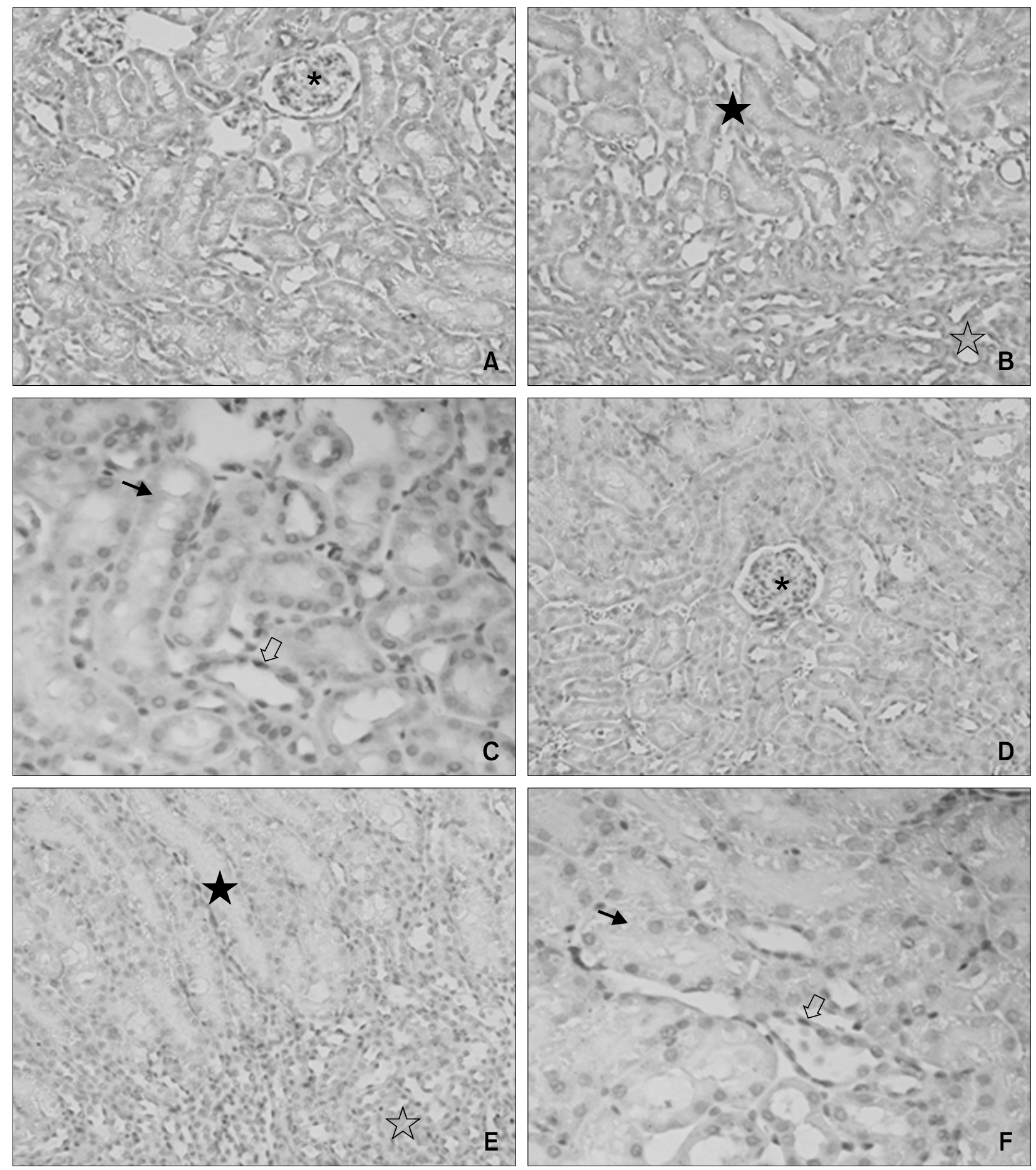

Figure 4. Immunohistochemical staining for CTGF in CT-treated and untreated mice. Immunohistochemical staining for CTGF was performed at $3 \mathrm{~h}$ after the intravenous injection of $C T(A, B, C)$ or vehicle $(D, E, F)$ into the tail of C57BL6 mice. Diffuse cytoplasm staining in tubule cells is seen $(A, B, C)$. All the untreated renal cells are immuno-negative $(D, E, F)$. A and D, $\times 40, B$ and E, $\times 100 ; C$ and F, $\times 200 ;{ }^{*}$, glomerulus; $\lesssim$, medulla; $\star$, cortex; $\rightarrow$, proximal tubule cell; $\Rightarrow$, distal tubule cell.

logical doses induces the expression of CTGF through ERK1/2 signaling in renal tubular epithelium. CT may play important roles in renal differen- tiation and wound healing by inducing various genes, including CTGF. These are new function of CT in the kidney. 


\section{Methods}

\section{Materials}

Salmon CT was purchased from Peninsula Laboratories, Inc. (Belmont, CA). PD98059 was from New England Biolabs, Inc. (Beverly, MA), cycloheximide was purchased from Sigma Chemical Co. (St. Louis, MO) and primary antibody against CTGF was from Torrey Pines Biolabs, Inc. (Houston, TX). Antibodies against phosphorylated and nonphosphorylated ERK1/2 were purchased from Cell Signaling Technology (Beverly, MA).

\section{Cell line and cell culture}

Porcine proximal kidney tubular cell line LLC-PK1 was obtained from the Japanese Cancer Research Resources Bank (Tokyo, Japan). LLC-PK1 cells were routinely cultured in RPMI 1640 medium with 10\% FBS (HyClone, Road Logan, UT) at $37^{\circ} \mathrm{C}$ with $5 \% \mathrm{CO}_{2}$.

\section{Animals}

Eight-month-old female C57BL/6 mice (Charles River, Sagamihara, Japan) were used. An intravenous injection of CT $\left(200 \mu\right.$ l of $10^{-5} \mathrm{M}$ stock $)$ or vehicle $(200 \mu$ isotonic saline solution) into the tail vein was performed. CT was dissolved in isotonic saline solution $(0.9 \% \mathrm{NaCl})$ containing 1.2 $\mathrm{M}$ aminocaproic acid ( $\mathrm{pH}$ 6.0) as peptidase inhibitor (Han et al., 2006). After $3 \mathrm{~h}$, the treated mice were killed and the kidneys were fixed in $4 \%$ glutaraldehyde solution at $4^{\circ} \mathrm{C}$ overnight. All protocols for in vivo studies were approved by the Institutional Animal Care and Use Committee of Wakayama Medical University.

\section{cDNA subtraction}

Suppression subtractive hybridization was performed using the Clontech PCR-Select cDNA Subtraction kit (CLONTECH, Palo Alto, CA). In brief, poly $(A)^{+}$RNA was prepared from LLC-PK1 cells that were treated with or without $10^{-8} \mathrm{M} \mathrm{CT}$ for $3 \mathrm{~h}$ using the mRNA Separator Kit (CLONTECH). Following the manufacturer's protocol, $1 \mu \mathrm{g}$ of RNA from each of the samples was used to prepare a population of subtracted cDNA clones from the cells treated with CT. Clones induced by CT were subcloned into PCR 2.1 vector using the TA cloning kit (Invitrogen, Carlsbad, CA). The ligation mixture was transfected into TOP10F' cells according to the manufacture's protocol (Invitrogen). Single colonies were picked and screened for inserts using PCR. Randomly picked clones were sequenced for inserts using nested PCR primer1 (CLONTECH) and sequences were submitted for BLAST analysis using public domain NCBI databases.

\section{Northern blot analysis}

After stimulation of LLC-PK1 cells with CT for various times, total RNA was extracted using the ULTRASPEC RNA Isolation System (Biotecx Laboratories, Inc., Houston, TX). Separation of total RNA (10 $\mu \mathrm{g} / \mathrm{lane})$ was achieved by electrophoresis in $1.2 \%$ agarose gels containing $1.9 \%$ formaldehyde with $1 \times$ MOPS as the running buffer Separated RNA was transferred to nylon membranes by capillary blotting and fixed by GS GENE LINKER (BIO-RAD Lab., Hercules, CA). Hybridization was performed with cDNA inserts labeled with $\left[{ }^{32} \mathrm{P}\right] \alpha$ ATP using the Hotprime DNA labeling kit (GeneHunter, Nashville, TN). Quantitative analysis of the autoradiograph was performed by the NIH Image densitometry program and normalized to the 18s rRNA stained with ethidium bromide.

\section{Cellular protein extraction and Western blot analysis}

LLC-PK1 cells were grown to $80 \%$ confluence and the medium was replaced with RPMI 1640 with $0.5 \%$ FBS for $18 \mathrm{~h}$. Afterwards, the cells were treated with a variety of agents. Cellular protein extraction was performed as previously described (Zhang et al., 1997) except that sonication was omitted. Protein concentrations were assayed using BCA Protein Assay Reagent (Pierce, Rockford, III). Twenty micrograms of total protein from each sample was analyzed by electrophoresis in a $10 \%$ SDS-polyacrylamide gel and transferred to a polyvinylidene fluoride membrane (Millipore, Bedford, MA). Membranes were incubated with primary antibody overnight at $4^{\circ} \mathrm{C}$ followed by incubation with the HRP-coupled anti-rabbit IgG secondary antibody (DAKO Glostrup, Denmark) (1:3000) at room temperature for $1 \mathrm{~h}$. Reactive proteins were detected using an ECL kit (Amersham, Buckinghamshire, England) according to the manufacturer's instructions.

\section{Immunohistochemistry}

Glutaraldehyde-fixed, paraffin-embedded sections of the kidneys were used for this study. Immunohistochemical staining was carried out using the indirect method with polyclonal antibodies against CTGF. Briefly, tissue sections of $4 \mu \mathrm{m}$ thickness were prepared. After deparaffinization and rehydration, endogenous peroxidase activity was blocked with a $1 \%$ solution of hydrogen peroxide in absolute methanol for $35 \mathrm{~min}$. For antigen retrieval, the sections were immersed in $1 \mathrm{mM}$ citrate-phosphate buffer, and microwaved at $100^{\circ} \mathrm{C}$ for $15 \mathrm{~min}$. The sections were incubated with $10 \mu \mathrm{g} / \mathrm{ml}$ anti-mouse CTGF polyclonal antibody for 30 min at $37^{\circ} \mathrm{C}$ using an automatic immunohistochemical staining system (VENTANA NX System NX-IHC/20; Ventana Medical Systems Japan, Inc., Tokyo, Japan). After reaction with a rabbit biotinylated secondary antibody, antigen-antibody was visualized using a streptavidin-HRP conjugate (DAKO LSAB kit; DAKO, Los Angeles, CA) with diaminobenzidine. Sections were counterstained with hematoxylin.

\section{Statistical analysis}

Determinations were performed in triplicate, and all experiments were repeated three times. Results are expressed as the mean \pm SEM. Statistical analysis was performed by one-way ANOVA. A P-value of $<0.05$ was considered statistically significant.

\section{Acknowledgements}

We thank Ms Emiko Taniguchi for preparing histologic 
sections.

\section{References}

Bijvoet OL, van der Sluys, Veer J, de Vries HR, van Koppen AT. Natriuretic effect of calcitonin in man. $\mathrm{N}$ Engl $\mathrm{J}$ Med 1971;284:681-8

Blom IE, van Dijk AJ, Wieten L, Duran K, Ito Y, Kleij L, deNichilo M, Rabelink TJ, Weening JJ, Aten J, Goldschmeding R. In vitro evidence for differential involvement of CTGF, TGFbeta, and PDGF-BB in mesangial response to injury. Nephrol Dial Transplant 2001;16:1139-48

Bork $P$. The modular architecture of a new family of growth regulators related to connective tissue growth factor. FEBS Lett 1993;327:125-30

Cano E, Hazzalin CA, Kardalinou E, Buckle RS, Mahadevan LC. Neither ERK nor JNK/SAPK MAP kinase subtypes are essential for histone H3/HMG-14 phosphorylation or c-fos and c-jun induction. J Cell Sci 1995;108:3599-609

Chakraborty M, Chatterjee D, Gorelick F, Baron R. Cell cycle-dependent and kinase-specific regulation of the apical $\mathrm{Na} / \mathrm{H}$ exchanger and the $\mathrm{Na}$, K-ATPase in the kidney cell line LLC-PK1 by calcitonin. Proc Natl Acad Sci USA 1994; 91:2115-9

Crean JK, Finlay D, Murphy M, Moss C, Godson C, Martin F, Brady HR. The Role of p42/44 MAPK and protein kinase $B$ in connective tissue growth factor induced extracellular matrix protein production, cell migration, and actin cytoskeletal rearrangement in human mesangial cells. J Biol Chem 2002;277:44187-94

Eddy AA. Molecular basis of renal fibrosis. Pediatr Nephrol 2000;15:290-301

Force T, Boneventre JV, Flannery MR, Gorn AH, Yamin M, Goldring SR. A cloned porcine renal calcitonin receptor couples to adenylyl cyclase and phospholipase C. Am J Physiol 1992;262:F1110-F5

Foster GV. Thyroid origin of calcitonin. Nature 1964;202: 1303-5

Hahn A, Heusinger-Ribeiro J, Lanz T, Zenkel S, GoppeltStruebe M. Induction of connective tissue growth factor by activation of heptahelical receptors. Modulation by Rho proteins and the actin cytoskeleton. J Biol Chem 2000;275: 37429-35

Han B, Nakamura M, Zhou G, Ishii A, Nakamura A, Bai Y, Mori I, Kakudo K. Calcitonin inhibits invasion of breast cancer cells: involvement of urokinase-type plasminogen activator (UPA) and uPA receptor. Int J Oncol 2006;28:807-14

Hazzalin CA, Le Panse R, Cano E, Mahadevan LC. Anisomycin selectively desensitizes signalling components involved in stress kinase activation and fos and jun induction. Mol Cell Biol 1998;18:1844-54

Heusinger-Ribeiro J, Eberlein M, Wahab NA, GoppeltStruebe M. Expression of connective tissue growth factor in human renal fibroblasts: regulatory roles of RhoA and cAMP. J Am Soc Nephrol 2001;12:1853-61
Igarashi A, Okochi H, Bradham DM, Grotendorst GR. Regulation of connective tissue growth factor gene expression in human skin fibroblasts and during wound repair. Mol Biol Cell 1993;4:637-45

Ishii A, Nakamura M, Nakamura A, Kimura M, Kakudo K. Localization of calcitonin receptor mRNA in rat kidney: an in situ hybridization study. Acta Histochem Cytochem 2004;37: 259-65

Ito Y, Aten J, Bende, RJ, Oemar BS, Rabelink TJ, Weening JJ, Goldshmeding R. Expression of connective tissue growth factor in human renal fibrosis. Kidney Int 1998;53:853-61

Jagger C, Gallagher T, Chambers T, Pondel MD. The porcine calcitonin receptor promoter directs expression of a linked reporter gene in a tissue and developmental specific manner in transgenic mice. Endocrinology 1999;140:492-9

Jagger C, Chambers T, Pondel MD. Transgenic mice reveal novel sites of calcitonin receptor gene expression during development. Biochem Biophys Res Commun 2000;274: 124-9

Kim HS, Nagalla, SR, Oh Y, Wilson E, Roberts CT Jr, Rosenfeld RG. Identification of a family of low-affinity insulin-like growth factor binding proteins (IGFBPs): characterization of connective tissue growth factor as a member of the IGFBP superfamily. Proc Natl Aca Sci USA 1997;94: 12981-6

Lau LF, Lam SC. The CCN family of angiogenic regulators: the integrin connection. Exp Cell Res 1999;248:44-57

Lin HY, Harris TL, Flannery MS, Aruffo A, Kaji EH, Gorn A, Kolakowski LF, Lodish HF , Goldring SR. Expression cloning of an adenylate cyclase-coupled calcitonin receptor. Science 1991;254:1022-4

McDermott MT, Kidd GS. The role of calcitonin in the development and treatment of osteoporosis. Endocr Rev 1987;8:377-90

Muff R, Kaufmann M, Born W, Fischer JA. Calcitonin inhibits phosphate uptake in opossum kidney cells stably transfected with a porcine calcitonin receptor. Endocrinology 1994;134: 1593-6

Nakamura M, Yang Q, Ozaki T, Nakamura Y, Yamasaki H, Mori I , Kakudo K. Induction of uPA but not NF-IL3A by calcitonin is dependent on Erk1/2 phosphorylation in porcine renal cell line LLC-PK1. Biochem Biophys Res Commun 2002;290:1483-8

Nakamura M, Han B, Nishishita T, Bai Y, Kakudo K. Calcitonin targets extracellular signal-regulated kinase signaling pathway in human cancers. J Mol Endocrinol 2007;39:37584

Pawar S, Kartha S, Toback FG. Differential gene expression in migrating renal epithelial cells after wounding. J Cell Physiol 1995;65:556-65

Ruiz-Deya G, Sikka SC, Thomas R, Abdel-Mageed AB. Potential role for the nuclear transcription factor NF-kappa $B$ in the pathogenesis of ureteropelvic junction obstruction. J Endourol 2002;16:611-5

Song Z, Ma N, Hayashi T, Gabazza EC, Sugimura Y, Suzuki 
K. Intracellular localization of protein $\mathrm{C}$ inhibitor $(\mathrm{PCl})$ and urinary plasminogen activator in renal tubular epithelial cells from humans and human $\mathrm{PCl}$ gene transgenic mice. Histochem Cell Biol 2007;128:293-300

Surveyor GA, Brigstock DR. Immunohistochemical localization of connective tissue growth factor (CTGF) in the mouse embryo between days 7.5 and 14.5 of gestation. Growth Factors 1999;17:115-24

Suzuma K, Naruse K, Suzuma I, Takahara N, Ueki K, Aiello L, King GL. Vascular endothelial growth factor induces expression of connective tissue growth factor via KDR, Flt1, and phosphatidylinositol 3-kinase-akt-dependent pathways in retinal vascular cells. J Biol Chem 2000;275:40725-31

Taraboletti G, Morigi M, Figliuzzi M, Giavazzi R, Zoja C, Remuzzi G. Thrombospondin induces glomerular mesangial cell adhesion and migration. Lab Invest 1992;67:566-71

Thomson SE, McLennan SV, Kirwan PD, Heffernan SJ Hennessy A, Yue DK, Twigg SM. Renal connective tissue growth factor correlates with glomerular basement mem- brane thickness and prospective albuminuria in a non-human primate model of diabetes: possible predictive marker for incipient diabetic nephropathy. J Diabetes Complications 2008;22:284-94

Xie S, Sukkar MB, Issa R, Oltmanns U, Nicholson AG, Chung KF. Regulation of TGF-beta 1-induced connective tissue growth factor expression in airway smooth muscle cells. Am J Physiol Lung Cell Mol Physiol 2005;288:L68-76

Yoshida N, Yoshida T, Nakamura A, Monkawa T, Hayashi M, Saruta T. Calcitonin induces 25-hydroxyvitamin D3 1alphahydroxylase mRNA expression via protein kinase $C$ pathway in LLC-PK1 cells. J Am Soc Nephrol 1999;10:2474-9

Zaidi MB, Moonga SP, Bevis J, Bascal ZA, Breimer LH. The calcitonin gene peptides: biology and clinical relevance. Crit Rev Clin Lab Sci 1990;28:109-74

Zhang R, Zhang H, Zhu W, Pardee AB, Coffey RJ Jr, Liang $P$. Mob-1, a Ras target gene, is overexpressed in colorectal cancer. Oncogene 1997;3:1607-10 